논 문 15-11-2

\title{
$\mathrm{Ar} / \mathrm{CF}_{4}$ 유도결합 플라즈마를 이용한 $\left(\mathrm{Ba}_{0.6} \mathrm{Sr}_{0.4}\right) \mathrm{TiO}_{3}$ 박막의 식각 특성
}

\section{The Etching Characteristics of $\left(\mathrm{Ba}_{0.6} \mathrm{Sr}_{0.4}\right) \mathrm{TiO}_{3}$ Films using $\mathrm{Ar} / \mathrm{CF}_{4}$ Inductively Coupled Plasma}

\author{
강필승*, 김경태", 김동표", 김창일", 이수재"* \\ (Pil-Seung Kang*, Kyoung-Tae Kim*, Dong-Pyo Kim*, Chang-II Kim*, and Su-Jae Lee")
}

\begin{abstract}
( $\mathrm{Ba}, \mathrm{Sr}) \mathrm{TiO}_{3}$ (BST) thin films on $\mathrm{Pt} / \mathrm{Ti} / \mathrm{SiO} / \mathrm{Si}$ substrates were deposited by a sol-gel method and the etch characteristics of BST thin films have been investigated as a function of gas mixing ratio. The maximum etch rate of the BST films was $440 \AA / \mathrm{min}$ under such conditions as; $\mathrm{CF}_{4} /\left(\mathrm{CF}_{4}+\mathrm{Ar}\right)$ of 0.2 , RF-power of $700 \mathrm{~W}, \mathrm{DC}$-bias voltage of $-200 \mathrm{~V}$, pressure of $15 \mathrm{mT}$ orr and substrate temperature of $30{ }^{\circ} \mathrm{C}$. The selectivities of $\mathrm{BST}$ to $\mathrm{Pt}, \mathrm{SiO}_{2}$ and $\mathrm{PR}$ were $0.38,0.25$ and 0.09 , respectively. In the XPS (X-ray photoelectron spectroscopy) analysis, Barium (Ba) and Strontium ( $\mathrm{Sr}$ ) component in BST thin films formed low volatile compounds such as BaFx, SrFx, which are forms by the chemical reaction with $\mathrm{F}$ atoms and is removed by $\mathrm{Ar}$ ion bombardment. Titanium ( $\mathrm{Ti}$ ) is removed by chemical reaction such as $\mathrm{TiF}$ with ease. The result of secondary ion mass spectrometry (SIMS) analysis confirmed the existence of the BaFx, SrFx, TiFx.
\end{abstract}

Key Words : BST, Sol-Gel, ICP, OES, XPS, SIMS

\section{1. 서 론}

Barium strontium titanate ((Ba,Sr) $\left.\mathrm{TiO}_{3} ; \mathrm{BST}\right)$ 박막은 기가 비트(giga bit)급 DRAMs (dynamic ramdom access memories) 메모리 셀을 구성하는 전하 축적 커패시터 (charge storage capacitor)의 새로운 유전체 물질로서 많은 주목을 받고 있다. BST 박막은 높은 유전율과 우수한 절연특성, 온도 에 대하여 상대적으로 작은 전기적 특성의 변화롤 가지고 있다. 또한 고유전율의 박막에서 나타나는

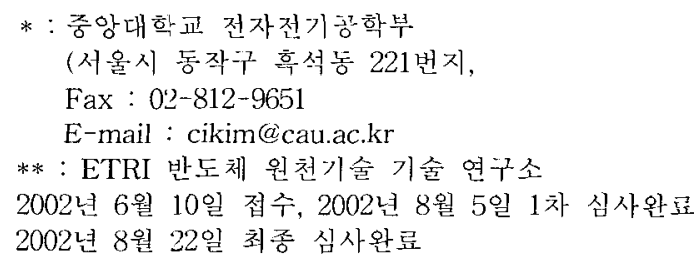

유전손실 (dielectric loss) 현상이 다론 고유전율의 물질보다 상대적으로 낮은 값을 가지고 있다[1]. 이러한 BST 박막은 형성에 대한 딶은 연구가 진 행되어 실제 소자에 적용이 가능한 안정된 $\mathrm{BST}$ 박막을 형성하는 단계에 이르렀다. 그러나 기가 비 트급의 DRAM을 실현하기 위해서는 높은 선택비 와 우수한 공정 제어로 비등방성 패터넝이 가능한 플라즈마 식각 공정 기술의 개발이 필수적이지만 이에 대한 연구는 미비한 실정이다[2].

본 논문에서는 졸겔법으로 성장된 BST 박막을 이용하였고, $\mathrm{BST}$ 박막의 식각울 $\mathrm{Ar} / \mathrm{CF}_{4}$ 유도 결합 플라즈마를 이용하여 수행하였다[3-4]. 식각조건은 $\mathrm{Ar}$ 과 $\mathrm{CF}_{4}$ 가스 혼합비의 변화에 따라 식각하였고, 이에 대한 식각속도의 변화를 관찰하였다. 식각 후 $\mathrm{BST}$ 박막의 표면에서 화학적인 반응을 고찰하기 위하여 XPS ( $\mathrm{x}$-ray photoelectron spectroscopy) 
분석을 수행하였으며, 이를 검증하기 위해 SIMS (Secondary ion mass spectrometry)를 이용하였다.

\section{2. 실 험}

본 실험에서 $\mathrm{BST}$ 종착을 위한 기판으로 0.85-1.15 $\Omega \mathrm{cm}$ 의 p형 실리콘 웨이퍼를 사용 하였 다. $\mathrm{Si}$ 기판을 $1: 4$ 의 $\mathrm{H}_{2} \mathrm{SO}_{4}: \mathrm{H}_{2} \mathrm{O}_{2}$ 및 $10: 1$ 의 $\mathrm{H}_{2} \mathrm{O}$ : $\mathrm{HF}$ 용액으로 자연 산화막을 제거 후 탈이 온수 (deionized water)로 세척하였다. TEOS (tetra-ethylorthosilicate) 막은 $420{ }^{\circ} \mathrm{C}$ 에서 $\mathrm{SiH}_{4}$ 및 $\mathrm{O}_{2}$ 가스를 사용한 저압 화학증착법 (LPCVD: low pressure chemical vapor deposition)으로 $2000 \AA$ 두깨로 증착하였다. TEOS막을 증착시킨 후 Pt 박 막의 점착력을 개선하기 위하여 $1000 \AA$ 의 $\mathrm{Ti}$ 막을 스퍼터 증착하였다. Ti막 위에 Varian 3180 스퍼터 링 시스템을 사용하여 상온, $6 \mathrm{mTorr}$ 분위기 하에 서 $\mathrm{Pt}$ 타겟을 사용하여 $2000 \AA$ 두께의 Pt 박막을 스퍼터링 하여 증착 하였다. $\mathrm{Pt}$ 박막을 증착한 후, $\mathrm{BST}$ 막은 sol-gel 방법으로 증착하였고, 최종 BST 박막의 두께는 $2500 \AA$ 이었다.

이와 같이 준비된 $\mathrm{BST}$ 박막을 $\mathrm{ICP}$ 식각장치를 이용하여 $\mathrm{Ar} / \mathrm{CF}_{4}$ 가스 혼합비를 변화시키면서 식 각하였다. 이때 $\mathrm{rf}$ 전력은 $700 \mathrm{~W}, \mathrm{dc}$ 바이어스 전 압을 $-250 \mathrm{~V}$, 반응로 압력은 $15 \mathrm{mTorr}$, 기판온도 는 $30{ }^{\circ} \mathrm{C}$ 로 고정하였다. 식각속도는 Tencor사의 $a$ -step-500을 이용하여 측정하였으며, 식각단면은 Hitachi사의 S-800 SEM을 이용하여 관찰 하였다. 식각 전후의 $\mathrm{BST}$ 박막의 표면반응을 $\mathrm{VG}$ Scientific 사의 ESCALAB 220-IXL XPS 장비를 이용하여 분석하였다. 이때 XPS 장비는 250 watts 의 $\mathrm{Al} \mathrm{Ka}(1486.6 \mathrm{eV})$ 방사를 사용하였다.

\section{3. 결과 및 고찰}

그림 1 은 $\mathrm{CF}_{4} / \mathrm{CF}_{4}+\mathrm{Ar}$ 가스의 혼합비에 따른 $\mathrm{BST}$ 박막의 식각 속도와 $\mathrm{SiO}_{2}, \mathrm{PR}$ (photoresist) 및 Pt에 대한 식각 선택비를 나타낸 것이다. 이때 코일의 rf 전력은 $700 \mathrm{~W}, \mathrm{dc}$ 바이어스전압은 -250 $\mathrm{V}$, 반웅로의 압력은 $15 \mathrm{mTorr}$ 로 고정 시켰다.

그림 1 에서 $\mathrm{CF}_{4} / \mathrm{Ar}$ 가스 혼합비가 $20 \%$ 까지 증가함에 따라 BST 박막의 식각률도 증가하였다. 그러나 $\mathrm{CF}_{4}$ 농도가 $20 \%$ 이상 증가함에 따라 BST 박막의 식각률은 점차 감소하였다. 순수한 $\mathrm{Ar}$ 만 을 이용하여 식각하는 것 보다 $\mathrm{Ar} 80 \%$ 와 $\mathrm{CF}_{4}$
$20 \%$ 의 조건에서 $\mathrm{BST}$ 의 식각속도는 $440 \AA / \mathrm{min}$ 으 로 가장 높았다. 이 결과는 BST를 식각하는대 있 어서 $\mathrm{Ar}$ 에 의한 스퍼터링과 $\mathrm{F}$ 에 의한 화학적인 식 각에 의해서 더욱 효율적으로 식각이 됨을 알 수 있다.

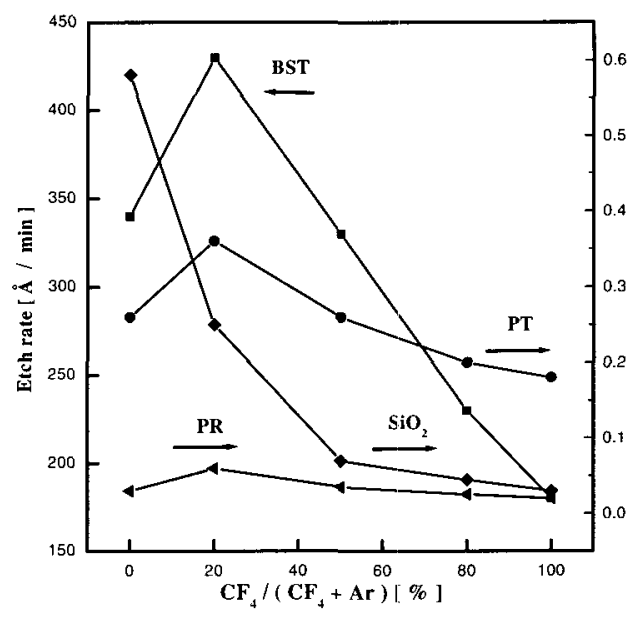

그림 1. $\mathrm{CF}_{4} /\left(\mathrm{CF}_{4}+\mathrm{Ar}\right)$ 가스 혼합비에 따라 식각된 $\mathrm{BST}$ 박막의 식각 속도 및 선택비.

Fig. 1. The etch rate of BST thin film and selectivities of $\mathrm{BST}$ to $\mathrm{Pt}, \mathrm{PR}$ and $\mathrm{SiO}_{2}$ as a function of $\mathrm{CF}_{4} / \mathrm{Ar}$ gas mixing ratios.

$\mathrm{CF}_{4} /\left(\mathrm{Ar}+\mathrm{CF}_{4}\right)$ 가 0.2 인 조건에서 $\mathrm{BST}$ 와 $\mathrm{Pt}$, $\mathrm{SiO}_{2}, \mathrm{PR}$ 의 식각 선택비는 각각 $0.38,0.25,0.09$ 이 었다. 이러한 식각 선택비는 실제 공정실험에 적용 하기에는 너무 낮은 값으로 BST 박막의 식각 마 스크 물질로는 하드마스크의 사용이 요구된다고 하겠다.

박막 표면에서 $\mathrm{BST}$ 박막의 원소인 $\mathrm{Ba}, \mathrm{Sr}, \mathrm{Ti}$ 및 $\mathrm{O}$ 의 원소들과 식각 gas 인 $\mathrm{CF}_{4}$ 의 $\mathrm{F}$ 와의 반 응을 연구하기 위하여, 다양한 가스의 혼합비에 따 라 식각된 BST 박막 표면을 XPS 분석을 수행하 였다. 그림 2는 $\mathrm{Ar} / \mathrm{CF}_{4}$ 가스혼합비를 다르게 하였 을 때 $\mathrm{Ba}, \mathrm{Sr}, \mathrm{Ti}, \mathrm{O}, \mathrm{C}, \mathrm{F}$ 의 상대적인 원소 비를 구한 것이다. $\mathrm{Ba}$ 과 $\mathrm{Sr}$ 의 경우예 $\mathrm{CF}_{4}$ 가 $80 \%$ 일 때 가장 적은 퍼센트를 나타낸다. 이는 $\mathrm{Ba}$ 과 $\mathrm{Sr}$ 은 $\mathrm{F}$ 라디칼과 화학적인 반응에 의해 식각되고, 또한 $\mathrm{Ar}$ 이온에 의한 스퍼터링의 효과가 도움을 주었다 고 판단된다. $\mathrm{Ti}$ 의 경우에는 $\mathrm{CF}_{4}$ 를 많이 첨가할수 록 원소비가 감소하는 것을 알 수 있는데 이는 $\mathrm{Ti}$ 
를 식각하는데 더욱 효과적인 것은 $\mathrm{Ar}$ 이온예 의 한 스퍼터링 효과에 의한 식각보다는 $\mathrm{F}$ 와의 화학 적인 반응에 의한 식각이 효과적임을 알 수 있다.

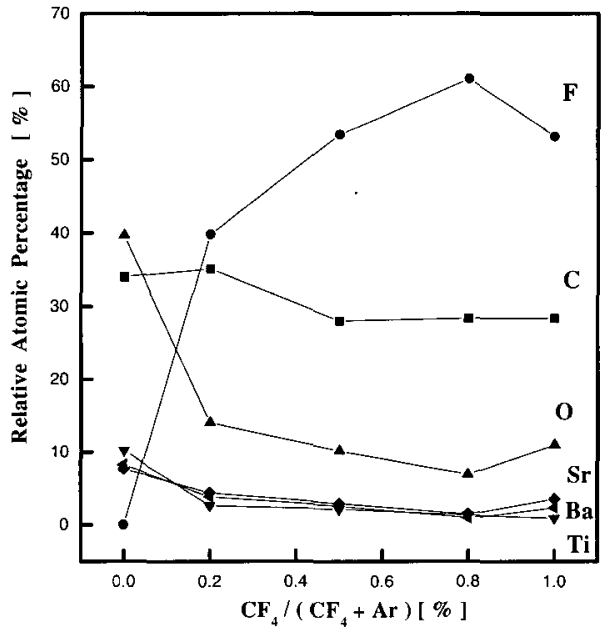

그림 2. 가스 혼합비에 따라 식각된 $\mathrm{BST}$ 박막 표 면의 상대적 원소비.

Fig. 2. A relative atomic percentages of etched BST thin film surface as a function of $\mathrm{CF}_{4} / \mathrm{Ar}$ gas ratios.

$\mathrm{O}$ 의 경우에는 $\mathrm{CF}_{4}$ 가 $80 \%$ 일 때 상대적으로 가 장 적은 양을 나타내고 있는데 이는 $\mathrm{O}$ 를 식각하기 위해서는 화학적인 식각이 더욱 효과적이고 또한, 스퍼터링에 의한 도움을 받는 것으로 생각할 수 있다. $\mathrm{F}$ 의 상대적인 원소비가 $\mathrm{CF}_{4}$ 의 첨가비를 $100 \%$ 로 한 것 보다 $\mathrm{CF}_{4}$ 의 비율이 $80 \%$ 에서 가장 많이 나타나는 이유는 어느 정도 $\mathrm{Ar}$ 이 첨가되었을 때 $\mathrm{Ar}$ 이돈과 $\mathrm{CF}_{4}$ 가스의 충돌에 의해 $\mathrm{C}$ 와 $\mathrm{F}$ 를 분리시키고 $\mathrm{F}$ 라디칼을 생성하는데 도움을 주기 때문인 것으로 판단된다. $\mathrm{CF}_{4}$ 의 가스가 높은 공정 조건에서 식각한 시로에서 $\mathrm{F}$ 의 상대적인 양이 많 은 것은 $\mathrm{CF}_{4}$ 의 첨가량이 많아질수록 그만큼 많이 생성된 $\mathrm{F}$ 라디칼들이 $\mathrm{Ba}, \mathrm{Sr}$ 과 결합을 하지 못하 고 식각된 $\mathrm{BST}$ 박막 표면에 남아 있어 passivation 되므로 식각을 저해하기 때문이라고 판단된다. 식각전의 시로예서 $\mathrm{C}$ 과 $\mathrm{F}$ 의 상대적인 원소비가 높은 것은 XPS 분석을 수행하기 전에 공기 중에 약 24 시간 정도 노출에 의한 오염일 것 이라 판단된다. $\mathrm{Ba}, \mathrm{Sr}, \mathrm{Ti}, \mathrm{O}$ 의 모든 경우에서 $\mathrm{Ar}$ 이 $20 \%, \mathrm{CF}_{4}$ 가 $80 \%$ 에서 상대적인 양이 가장 적게 나타나는데 Ar이 $80 \%$ 에서 BST 박막의 가장 높은
식각률이 나타나는 이유는 $\mathrm{F}$ 과의 화학적인 결합을 하고 있지만 $\mathrm{Ba}, \mathrm{Sr}$ 과 $\mathrm{F}$ 이 결합한 화합물들이 낮 은 휘발성으로 기인하여 쉅게 제거되지 않고 이들 물질이 표면에 많이 쌓이기 때문인 것으로 판단된 다. 이를 제거하기 위해서는 $\mathrm{Ar}$ 이온에 의한 스퍼 터링이 중요한 역할을 한다고 생각된다[5]. 이러한 결과를 통해서 알 수 있듯이 BST 박막의 식각률 을 높이기 위해서는 스퍼터링 효과 뿐만 아니라, 식각가스와 $\mathrm{Ba}, \mathrm{Sr}$ 이 반응하여 더욱 휘발성이 높 은 화합물을 만들도록 하여야만 한다는 것을 알 수 있다. $\mathrm{Sr}$ 의 경우 박막을 증착한 후에는 상대적 으로 가장 적은 양을 나타내고 있으나 식각한 후 에는 상대적으로 더욱 많은 양이 남아 있는데, 이 러한 결과로 보아 BST 박막을 효율적으로 식각하 기 위해서는 $\mathrm{Sr}$ 의 식각을 보다 효율적으로 해야만 함을 알 수 있다.

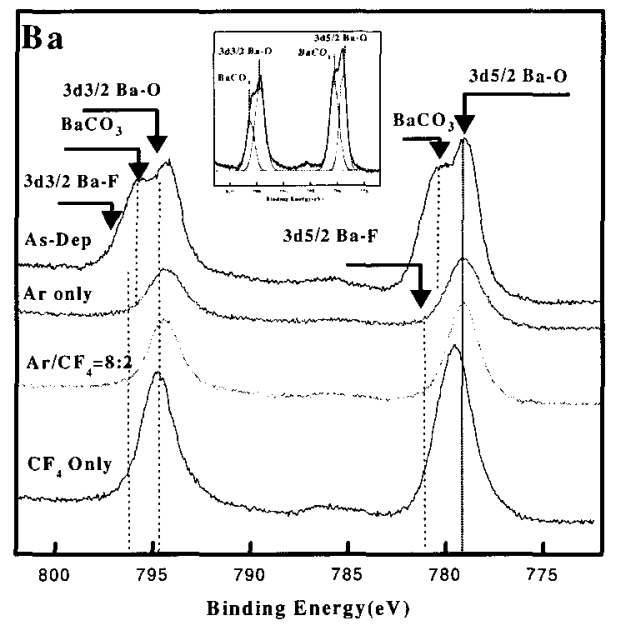

그림 3. $\mathrm{CF}_{4} /\left(\mathrm{CF}_{4}+\mathrm{Ar}\right)$ 가스 혼합비에 따라 식각된 $\mathrm{BST}$ 박막 표면의 $\mathrm{Ba} 3 \mathrm{~d}$ XPS narrowscan 스펙트럼.

Fig. 3. Ba 3d XPS narrow scan spectra of etched BST thin film surface as a function of $\mathrm{CF}_{4} / \mathrm{Ar}$ gas ratio.

식각된 $\mathrm{BST}$ 박막의 표면에서 $\mathrm{F}$ 와 $\mathrm{Ba}, \mathrm{Sr}, \mathrm{Ti}$ 의 화학적 결합을 분석하기 위하여 $\mathrm{Ar} / \mathrm{CF}_{4}$ 의 가스 혼 합비에 따라 XPS narrow scan 분석을 수행하였 다. 그림 3 은 $\mathrm{Ar} / \mathrm{CF}_{4}$ 가스 혼합비에 따라 식각된 BST 박막표면의 Ba 3d XPS narrow scan 스펙트 럼을 나타낸 것이다. 그림 3 에서 보인 바와 같이 $\mathrm{Ba} 3 \mathrm{~d}$ 피크는 $\mathrm{Ba}-\mathrm{O}$ 와 $\mathrm{Ba}-\mathrm{F}$ 의 피크로 분리되어 
나타난다. $\mathrm{As}-\mathrm{dep}$ 상태에서 $\mathrm{Ba} 3 \mathrm{~d}$ 의 결합에너지 는 $\mathrm{Ba}-\mathrm{O}\left(3 \mathrm{~d}_{5 / 2}\right)$ 와 $\mathrm{Ba}-\mathrm{O}\left(3 \mathrm{~d}_{3 / 2}\right)$ 에서 각각 $779.4 \mathrm{eV}$ 와 $794 \mathrm{eV}$ 으로 나타났다. 그러나 결합에너지 781 $\mathrm{eV}$ 에서는 독특한 피크가 발생하였다. 이는 졸겔 법으로 $\mathrm{BST}$ 를 제작하고 $\mathrm{O}_{2}$ 열처리하는 과정에서 $\mathrm{BST}$ 표면에 생기는 오염원에 의한 것이라 사료된 다. $\mathrm{Sr}$ 과 $\mathrm{Ti}$ 의 경우 이러한 반응이 일어나지 않 지만 $\mathrm{Ba}$ 의 원소특성상 $\mathrm{C}, \mathrm{O}$ 와 같은 원소와 반응하 여 형성되는 것으로 사료된다[7]. 이러한 오염원들 은 박막의 표면에 존재하기 때문에 식각 후 이러 한 오염원은 플라즈마의 스퍼터링 작용과 화학적 반응으로 제거 된다. $\mathrm{Ar}$ 만을 이용하여 식각 하였 을 때 $\mathrm{Ba}$ 피크는 화학적 결합 없이 $\mathrm{Ba}$ 피크가감 소하고, $\mathrm{CF}_{4}$ 를 $20 \%$ 첨가하였을때 $\mathrm{Ba}-\mathrm{F}$ 의 결합이 발생하는지 구별하기는 어렵지만, $\mathrm{CF}_{4}$ 만으로 식 각시 $\mathrm{Ba}$ 이 $\mathrm{F}$ 와 결합하여 $\mathrm{Ba}-\mathrm{F}$ 의 피크가 나타닜 다. 이는 SIMS 분석을 이용하여 검증하였다. $\mathrm{Ba}$ 의 화합물의 식각은 $\mathrm{F}$ 라디칼에 의한 화학적인 반응 과 $\mathrm{Ar}$ 스퍼터링 효과예 의존한다고 판단된다.

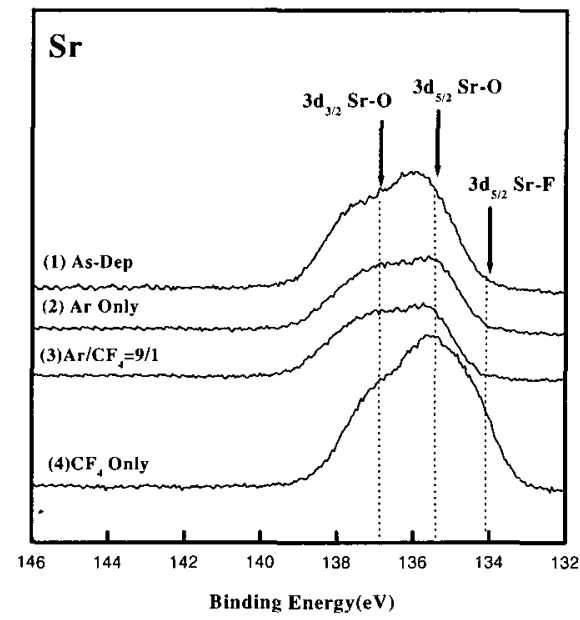

그림 4. $\mathrm{CF}_{4} /\left(\mathrm{CF}_{4}+\mathrm{Ar}\right)$ 가스 혼합비에 따라 식각된 $\mathrm{BST}$ 박막 표면의 $\mathrm{Sr} 3 \mathrm{~d}$ XPS narrow scan 스펙트럼.

Fig. 4. Sr 3d XPS narrow scan spectra of etched BST thin film surface as a function of $\mathrm{CF}_{4} / \mathrm{Ar}$ gas ratio.

그림 4 는 $\mathrm{Ar} / \mathrm{CF}_{4}$ 가스 혼합비에 변화에 따라 식 각된 $\mathrm{BST}$ 박막 표면의 $\mathrm{Sr} 3 \mathrm{~d}$ 의 스펙트럼을 나타 낸 것이다. 그림 4에서 보인 바와 같이 $\mathrm{Sr} 3 \mathrm{~d}$ 피크 는 $\mathrm{Sr}-\mathrm{O}\left(3 \mathrm{~d}_{3 / 2}\right)$ 와 $\mathrm{Sr}-\mathrm{O}\left(3 \mathrm{~d}_{5 / 2}\right)$ 의 결합에너지는 각각
$136.9 \mathrm{eV}$ 과 $135.03 \mathrm{eV}$ 에서 나타내었다. $\mathrm{Ar}$ 만을 이 용하여 식각한 경우는 화학적 반응없이 $\mathrm{Sr} 3 \mathrm{~d}$ 의 피크가 감소되었고, $\mathrm{CF}_{4}$ 를 $20 \%$ 첨가하여 식각 하 였을 때 $\mathrm{F}$ 라디칼과 $\mathrm{Sr}$ 의 화학적 결합과 $\mathrm{Ar}$ 스퍼 터링 작용에 의해 제거함으로싸 $\mathrm{Ar}$ 만으로 식각된 경우와 차이가 없다고 판단된다. 그러나 $\mathrm{CF}_{4}$ 만을 이용하여 식각 할 경우 $\mathrm{Sr}-\mathrm{F}$ 피크의 결합에너지가 $134.05 \mathrm{eV}$ 이며, 이 피크 전체의 세기가 as-dep 상 태보다 커지며 $\mathrm{Sr}-\mathrm{F}$ 의 결합이 분명하게 나타나였 다. 이는 $\mathrm{CF}_{4}$ 가스 중에 $\mathrm{F}$ 라디칼에 의해 $\mathrm{BST}$ 표 면에서 반응이 $\mathrm{SrF}$ 를 형성하였음을 알 수 있다.

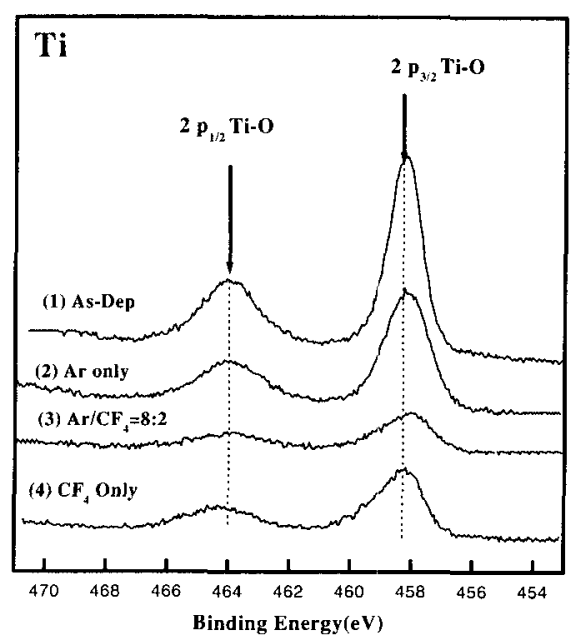

그림 5. $\mathrm{CF}_{4} /\left(\mathrm{CF}_{4}+\mathrm{Ar}\right)$ 가스 혼합비에 따라 식각된 $\mathrm{BST}$ 박막 표면의 $\mathrm{Ti} 3 \mathrm{~d}$ XPS narrow scan 스펙트럼.

Fig. 5. Ti 3d XPS narrow scan spectra of BST thin film surface etched as a function of $\mathrm{CF}_{4} / \mathrm{Ar}$ gas ratio.

그림 5는 $\mathrm{Ar} / \mathrm{CF}_{4}$ 가스 혼합비에 변화에 따라 식 각된 BST 박막 표면의 Ti 2p XPS narrow scan 스펙트럼을 나타낸 것이다. 그림 5 에서 보인 바와 같이, $\mathrm{Ti} 2 \mathrm{p}$ 피크는 $\mathrm{TiO}(2 \mathrm{p} 3 / 2)$ 와 $\mathrm{TiO}(2 \mathrm{p} 1 / 2)$ 결합 에너지는 각각 $458 \mathrm{eV}$ 과 $464 \mathrm{eV}$ 에서 나타내었다. $\mathrm{Ar}$ 만을 이용하여 식각한 경우 피크는 as-dep 상 태보다 감소하였지만, $\mathrm{CF}_{4}$ 를 $20 \%$ 첨가 하여 식각 한 경우 $\mathrm{Ti} 2 \mathrm{p}$ 피크는 더욱 더 감소하였다. 이는 $\mathrm{Ti}$ 의 식각은 $\mathrm{Ti}$ 와 $\mathrm{F}$ 라디칼의 화학적인 반응으 로 휘발성이 콘 $\mathrm{TiF}_{4}$ 결합을 형성하여 용이하게 제거되는 것으로 판단된다[8]. $\mathrm{CF}_{4}$ 만을 이용하여 식각한 경우, $\mathrm{Ti}$ 표면에 $\mathrm{F}$ 라디칼과 결합한 $\mathrm{TiFx}$ 
의 결합에너지가 $464.6 \mathrm{eV}$ 에서 나타났다. 이는 $\mathrm{TiF}_{3}$ 와 같은 비휘발적인 결합형태가 우세해지고 표면에 잔류하여 형성된 것이라 판단된다.

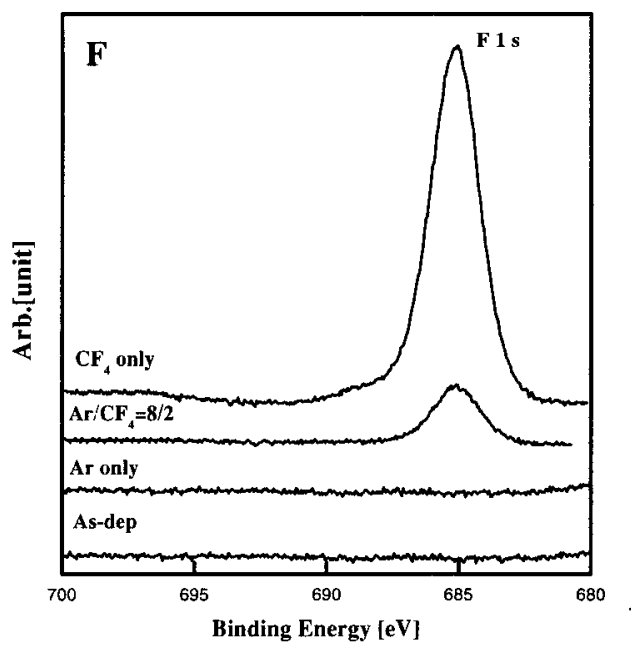

그림 6. $\mathrm{CF}_{4} /\left(\mathrm{CF}_{4}+\mathrm{Ar}\right)$ 가스 혼합비에 따라 식각된 BST 박막 표면의 F $1 S$ XPS narrow scan 스펙트럼.

Fig. 6. F 1s XPS narrow scan spectra of etched BST thin film surface as a function of $\mathrm{CF}_{4} / \mathrm{Ar}$ gas ratio.

그림 6 은 $\mathrm{Ar} / \mathrm{CF}_{4}$ 가스 혼합비에 변화에 따라 식 각된 BST 박막 표면의 F 1s XPS narrow scan 스펙트럼을 나타낸 것이다. 그림 6에서 보인 바와 같이 $\mathrm{F}$ 퍼크는 $\mathrm{F}$-metal $(\mathrm{BaF}, \mathrm{SrF}, \mathrm{TiF}$ ) 피크는 $684 \mathrm{eV}-685 \mathrm{eV}$ 의 결합에너지 범위에서 나타내었 다. 따라서 어떠한 결합의 피크가 우세한지 구분하 기 어렵고 다만 $\mathrm{CF}_{4}$ 가스를 첨가하여 식각할수록 $\mathrm{F}$ 라디칼의 증가함에 따라 $\mathrm{F}-\mathrm{metal}$ 결합의 피크가 중첩되어 나타남으로써 $\mathrm{F}$ 피크의 세기가 증가되었 다고 판단된다.

그림 7 은 $\mathrm{Ar} / \mathrm{CF}_{4}=8 / 2$ 조건에서 식각된 $\mathrm{BST}$ 박막의 표면에 대하여 SIMS 분석한 결과이다. $\mathrm{Ar} / \mathrm{CF}_{4}$ 가스를 사용하여 $\mathrm{BST}$ 박막 식각시에는 $\mathrm{Ar}$ 이온에 의한 스퍼터링과 $\mathrm{F}$ 라디칼에 의한 화학 적인 반응에 의한 효과가 서로 도움을 주어 $\mathrm{BST}$ 박막이 식각 된다는 것은 그림 1 과 그림2에서 설 명하였다. BST 박막은 원소가 $\mathrm{F}$ 라디칼과 $\mathrm{Ba}$, $\mathrm{Sr}, \mathrm{Ti}$ 반응하고, 이들 결합을 $\mathrm{Ar}$ 이온에 의한 스 퍼터링으로 각각의 결합된 형태 $(\mathrm{Ba}-\mathrm{F}, \mathrm{Sr}-\mathrm{F}$,
$\mathrm{Ti}-\mathrm{F})$ 로 식각된다. 식각된 $\mathrm{BST}$ 박막표면은 $\mathrm{BaO}$, $\mathrm{Ba}-\mathrm{Ti}-\mathrm{O}, \mathrm{Sr}-\mathrm{O}, \mathrm{Sr}-\mathrm{Ti}-\mathrm{O}, \mathrm{TiO}_{2}$ 등으로 결합하고 있음을 확인 할 수 있다.

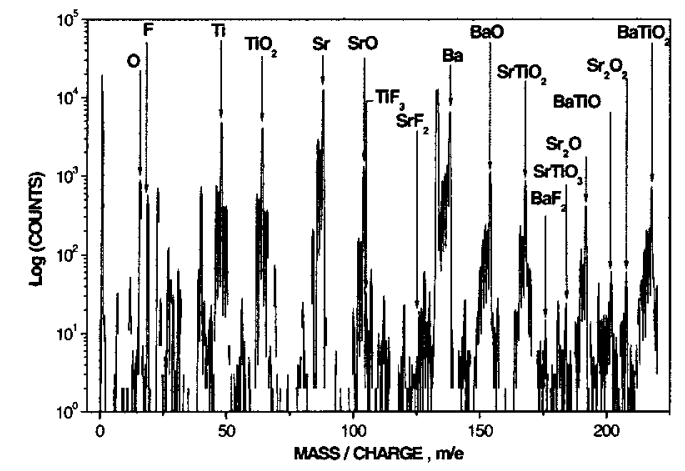

그림 7. $\mathrm{CF}_{4} /\left(\mathrm{CF}_{4}+\mathrm{Ar}\right)=0.2$ 의 가스 혼합비에 따라 식각된 $\mathrm{BST}$ 박막의 질량분석.

Fig. 7. Mass analysis of the etched BST thin film surface using SIMS at $\mathrm{CF}_{4} /\left(\mathrm{CF}_{4}{ }^{-}\right.$ $+\mathrm{Ar})=0.2$

$\mathrm{Ar}$ 이온의 스퍼터링에 의하여 $\mathrm{Ba}-\mathrm{O}, \mathrm{Sr}-\mathrm{O}$, $\mathrm{Ti}-\mathrm{O}, \mathrm{Ba}-\mathrm{Ti}-\mathrm{O}, \mathrm{Sr}-\mathrm{Ti}-\mathrm{O}$ 의 결합을 끊고, $\mathrm{Ba}, \mathrm{Sr}$, $\mathrm{Ti}$ 는 $\mathrm{BaF}_{2}, \mathrm{SrF}_{2}, \mathrm{TiF}_{3}, \mathrm{TiF}_{4}$ 의 형태로 결합하여 식각된다. $\mathrm{F}$ 라디칼과 결합한 $\mathrm{Ba}, \mathrm{Sr}$ 의 경우에는 비휘발 특성을 가지므로 $\mathrm{Ar}$ 이온에 의한 스퍼터링 의 효과로 제거 되고, $\mathrm{Ti}$ 의 경우에는 비교적 높은 비휘발 톡성을 나타내기 때문에 $\mathrm{Ti}-\mathrm{F}$ 는 쉽게 제거 될 수 있다고 판단된다.

\section{4. 결 론}

졸겔법을 이용하여 성장된 $\left(\mathrm{Ba}_{0.6} \mathrm{Sr}_{0.4}\right) \mathrm{TiO}_{3}$ 박막 을 ICP 식각 시스템에서 $\mathrm{Ar} / \mathrm{CF}_{4}$ 가스 플라즈마를 이용하여 식각하였다. BST 박막의 식각조건은 $700 \mathrm{~W}$ 의 rf 전력, $-250 \mathrm{~V}$ 의 바이어스 전압, 내부압 력은 $15 \mathrm{mTorr}, \mathrm{CF}_{4} /\left(\mathrm{CF}_{4}+\mathrm{Ar}\right)$ 가스 혼합비가 $20 \%$ 일 때 $440 \AA / \mathrm{min}$ 으로 최대 식각속도를 나타내었 다. 식각속도가 최대일 때 $\mathrm{PR}$ 과의 선택비는 0.09 이고, $\mathrm{SiO}_{2}$ 와의 선택비는 $0.25, \mathrm{BST}$ 와 $\mathrm{Pt}$ 의 선택 비는 0.38 이었다. XPS 와 SIMS 분석을 통해서 식 각된 $\mathrm{BST}$ 박막은 $\mathrm{F}$ 라디칼과 반응으로 $\mathrm{BaF}, \mathrm{SrF}$ 를 형성하며 이러한 물질은 비휘발성 이므로 $\mathrm{Ar}$ 이온에 의한 스퍼터링 작용으로 $\mathrm{BaF}, \mathrm{SrF}$ 반응물 
을 제거 하게 된다. $\mathrm{Ti}$ 의 경우에는 $\mathrm{Ar}$ 에 의한 물 리적 식각보다는 $\mathrm{F}$ 라디칼에 의한 반응으로 $\mathrm{TiF}_{4}$ 같은 휘발성 물질로 결합하여 식각된다.

\section{감사의 글}

이 논문은 2001 년도 한국학술진흥재단의 지원 에 의하여 연구되었음 (KRF-2001-042-E00042)

\section{참고 문헌}

[1] 류정선, 강성준, 윤영섭, "ULSI DRAM의 capacitor 절연막용 BST(Barium Strontium Titanate)박막의 제작과 톡성에 관한 연구", 전기전자재료학회지, 9권 4호, p. 336, 1996.

[2] 민병준, 김창일, 장의구, "유도 결합 폴라즈마 를 이용한 $\mathrm{YMnO}_{3}$ 박막의 건식 식각 특성연 구”, 한국전기전자재료학회논문지, 14권, 2호, p. $93,2001$.

[3] 안태현, 서용진, 김창일, 장의구, "고밀도 플라 즈마에 의한 PZT 박막의 식각특성 연구”, 한 국전기전자재료학회논문지, 13 권, 3 호, p. 188 , 2000.

[4] 유석빈, 김남훈, 김창일, 장의구, “도핑되지 않 은 비정질 실리콘의 고밀도 $\mathrm{Cl}_{2} / \mathrm{HBr}$ 플라조 마에 의한 식각 시 나칭 효과", 전기전자재로 학 회논문지, 13 권, 8 호, p. $651,2000$.

[5] S. B Kim, C. I. Kim, E. G. Chang, and G. Y. Yeom, "Study on surface reaction of $(\mathrm{Ba}, \mathrm{Sr}) \mathrm{TiO}_{3}$ thin films by high density plasma etching", J. Vac. Sci. Tech., A 17, p. $2156,1999$.

[6] W. J. Lee, C. R, S. H Kim, I. K You, and B. W Kim, "Etching Behavior and Damage Recovery of $\mathrm{SrBi}_{2} \mathrm{Ta}_{2} \mathrm{O}_{9}$ Thin Films", J. J. Appl, phys., Vol. 38, p. L1428, 1999.

[7] Y. F, Y. G, and Y. M, "Anlysis of Decomposed layer appearing on the surface of barium strontium titanate", J. J. Appl, phys., Vol. 38 p. L52, 1999.

[8] Handbook of X-ray Photoelectron Spectroscopy, edited by J. Chastain (Perkin Elmer), p. $72,1992$. 